\title{
Finite element modelling of monotonic pull-out test of deformed steel rebar embedded in well-confined concrete
}

\author{
Patria Kusumaningrum $^{1 *}$, Gigih Muslim Prayogo ${ }^{2}$, and Sri Tudjono ${ }^{3}$ \\ ${ }^{1}$ Structural Engineering Research Group, Faculty of Civil and Environmental Engineering, Bandung Institute of Technology, \\ Indonesia \\ ${ }^{2}$ Civil Engineering Master Program, Faculty of Civil and Environmental Engineering, Bandung Institute of Technology, \\ Indonesia \\ ${ }^{3}$ Civil Engineering Department, Faculty of Engineering, Diponegoro University, Semarang, Indonesia
}

\begin{abstract}
A finite element study carried out using LS DYNA and aimed to simulate the monotonic pull-out test of deformed steel rebar embedded in concrete is presented in this paper. Three models of the interface between deformed steel rebar and well-confined concrete, i.e. perfect bond model and two bond-slip models are observed and compared. Bond stress-slip response and rebar stress-slip response obtained numerically are validated with experimental data and empirical equations available from the literature. The full bond model overestimates the response, providing higher rebar stress. In the bond-slip models, good agreement is observed between numerical and experimental bond stress and rebar Stress-slip responses. The empirical equation of bond-slip proposed by Murcia-Delso and Shing (2014) is found to overestimate the peak bond stress.
\end{abstract}

\section{Introduction}

Reinforced concrete (RC) material is a composite material of concrete that has relatively low tensile strength and steel rebar to compensate for the ductility of the component with its high tensile strength and ductility. As it composes of two different materials, the interface between the concrete and steel becomes the weak part. When an RC component is loaded incrementally, stresses are gained and gradually increased all over parts of the component. As a weak link, the crack appears within this interface and stress will increase towards its capacity as the limiting value. In such a location, once the stress reaches its interface capacity, i.e., maximum bond stress, the transmitted stress between steel and concrete begins to drop to zero. At this stage, steel and concrete are unbounded, it is disconnected and no longer works as a unity. When the load is further increased, the unbounded interface grows and affects the overall structural behavior of RC components, both its load-carrying capacity and ductility/displacement.

To fully capture the accurate structural behavior of an RC component under specific loading, the bond-slip mechanism needs to be considered in the numerical model. A full bond model between steel and concrete may result in the overestimation of the structural capacity. Much past research has been made to study the bond mechanism through experimental testing and empirical analysis [1,2,3] and numerical modeling [4]. In this paper, the study is carried out numerically by finite element modeling to address this problem and to simulate the monotonic pull-out test of deformed steel rebar embedded in concrete. One of the full bond and two bond-slip models are analyzed and presented in this paper.

\section{Bond Slip Mechanism}

The bond-slip mechanism studied in this paper is based on experimental work done by $\mathrm{Xu}$ et al. (2017) [1]. The deformed rebar is well-confined concrete was monotonically loaded with a tensile force to form pull out test. The bond stress transfer at the interface between steel and concrete is represented by at least three mechanisms, i.e., adhesion, mechanical interaction, and friction.

\subsection{Adhesion}

Adhesion mechanism is formed during the concrete curing process by the chemical reaction of concrete, creating bonds and stresses to the rebar. This mechanism is significant to the bond stress transfer in the case of plain bars which have smooth surfaces. The failure of the adhesion stress transfer mechanism is occurred as crack initiates and propagates at the interface. In the case of deformed rebars, as studied herein, the adhesion mechanism is not significant to the stress transfer mechanism.

\footnotetext{
*Corresponding author: patria@si.itb.ac.id
} 


\subsection{Mechanical Interaction and Friction}

In the case of deformed steel bars, the bond stress transfer mechanism is primarily due to the combination of the mechanical interaction and friction between deformed ribs and the concrete surrounding them. As the axial load increases, the force transfer mechanism is dominated mainly by the mechanical interaction at the deformed steel rebar ribs. At one point, microcracks start to form at the ribs in a transversal direction, perpendicular to the direction of the loading. When the axial load is further increased, cracks grow wider and hence become macro transverse cracking. The area of conical shape where transverse cracking extended within finite depth surrounding the deformed bar is called a bond zone. As the transverse cracking progresses, the concrete adjacent to the deformed bar forms inclined compression cone struts. The strut rotates, forming radial contact forces. When the concrete is insufficiently confined, it may result in splitting failure which may further spread the damage outside of the bond zone. As the concrete in this study is well confined, no splitting failure is observed at the surface.

When the stress is near to the bond stress, longitudinal cracking takes place and bond zone dilation is observed. Once the peak is reached, stress-strain softening is observed due to progressive shear failure of concrete between the deformed ribs. Fig. 1 shows the condition of the specimen post-experiment [1]. No splitting failure was observed at the surface, and the steel rebar was still in the elastic stage. The failure is herein governed by the concrete adjacent to the contact area. Hence, the bond-slip stress is deduced using the following equation:

$$
\tau=\frac{F}{\pi \cdot l_{e} \cdot d}
$$
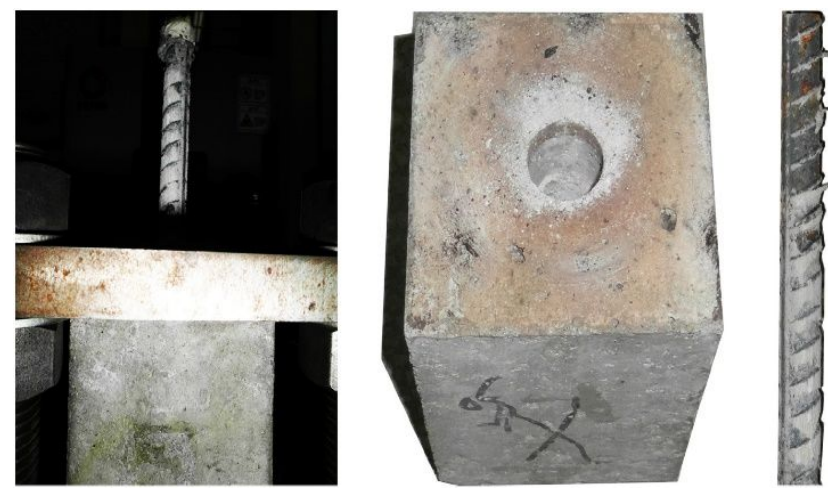

Fig 1. Bond Failure Pattern of Specimen Observed Experimentally [1]

\section{Finite Element Modeling}

\subsection{Model Set-Up}

The finite element modeling is carried out using explicit analysis by licensed LS DYNA software to model the monotonic pull-out test of the deformed steel rebar embedded in well-confined concrete. The set-up of the finite element model as shown in Fig. 2 follows the detail of the experimental setup for the local bond-slip test conducted by $\mathrm{Xu}$ et al. (2017) [1]. Well, a confined concrete specimen of size $100 \mathrm{~mm} \times 100 \mathrm{~mm} \times 140 \mathrm{~mm}$ with installed stirrups was cast together with the deformed steel rebar of $16 \mathrm{~mm}$ nominal diameter inserted in the center of the concrete specimen. The stirrups were added to the specimen to prevent the splitting of concrete; hence, the pull-out failure was achieved. The bonded length between rebar and concrete was $80 \mathrm{~mm}$; or 5 times the nominal diameter. Displacement control is carried out to perform the monotonic pull-out test. The well confined concrete specimen was clamped by the top and bottom steel plates. Surface to surface contact algorithm is invoked to simulate the interaction between the steel plates and the concrete.

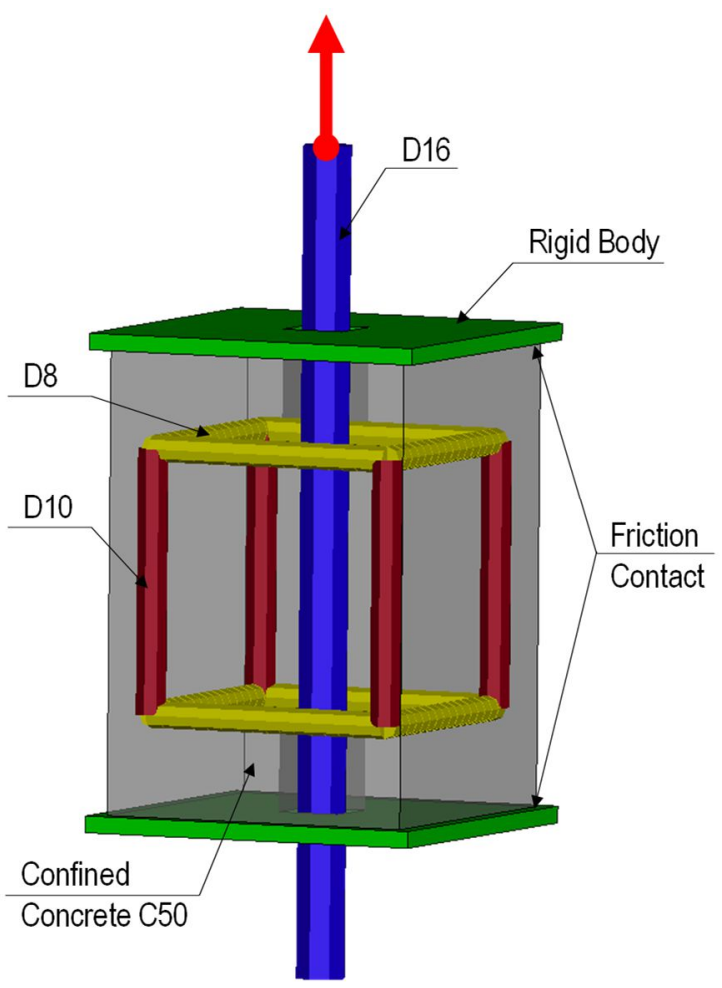

Fig 2. Pull-out Test Set Up Model

\subsection{Concrete Material}

There are at least four material models in LS DYNA that can be utilized to model concrete material, i.e., K\&C Concrete Damage Release III (Mat 072 Rel. III), Winfrith Concrete (Mat 084), Continuous Surface Cap (CSCM, Mat 145) and Concrete Damage Plasticity (CDPM, Mat 273). Among others, Concrete Damage Plasticity Material (CDPM) is observed to be able to capture the compressive hardening and softening as well as tension stiffening for the monotonic loading condition. This material is also observed to be good at modeling the degradation of stiffness in the hysteretic curve during the loading and unloading cycles. Therefore, in this study CDPM is incorporated to model concrete material.

As for the element type, concrete is modeled as a 3D solid element with a reduced integration point. Hence, to 
avoid shear locking, the hourglass control FlanaganBelytschko stiffness form [5] with a significantly small hourglass coefficient of 0.02 is invoked. The hourglass coefficient is adjusted and optimized following the optimized mesh size from the sensitivity analysis. It is carried out by controlling the amount of hourglass energy produced, which should be less than $10 \%$ of the total internal energy. The high value of the hourglass coefficient is not recommended to be used with the stiffness form as it may stiffen the structural response.

Material regularization is carried out before FEA, and the stress-strain relations of concrete material incorporated in the FEA model are given in the following Figures. Fig. 3 shows the compressive stress-strain relation of concrete of $55 \mathrm{MPa}$ compressive strength. The maximum compressive strength is obtained from the experiment [1]. The tensile behavior of concrete material is given in Fig. 4. Both the maximum tensile strength and the fracture energy of the concrete material follow the empirical equations provided by CEB FIP as given in Fig. 5.

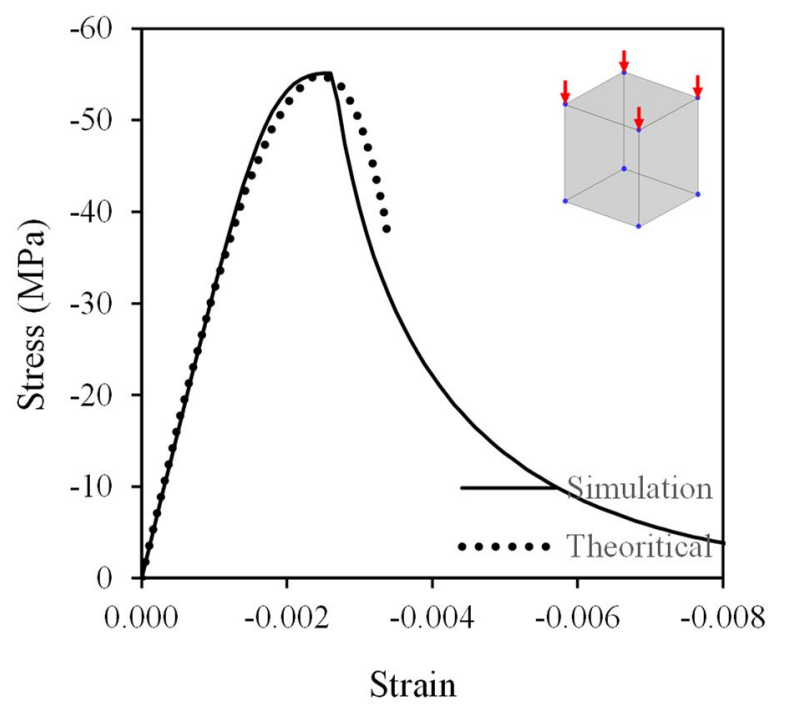

Fig 3. Compressive Stress Input of Concrete CDPM

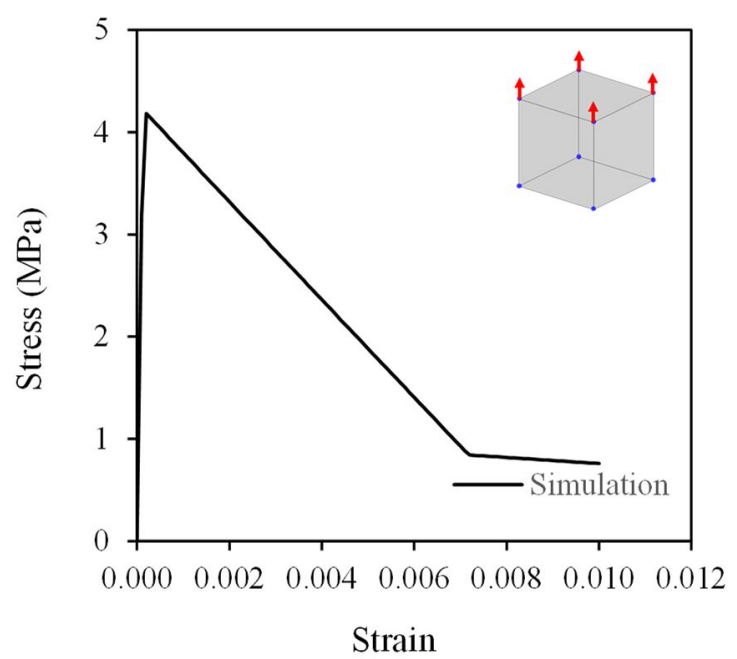

Fig 4. Tensile Stress Input of Concrete CDPM

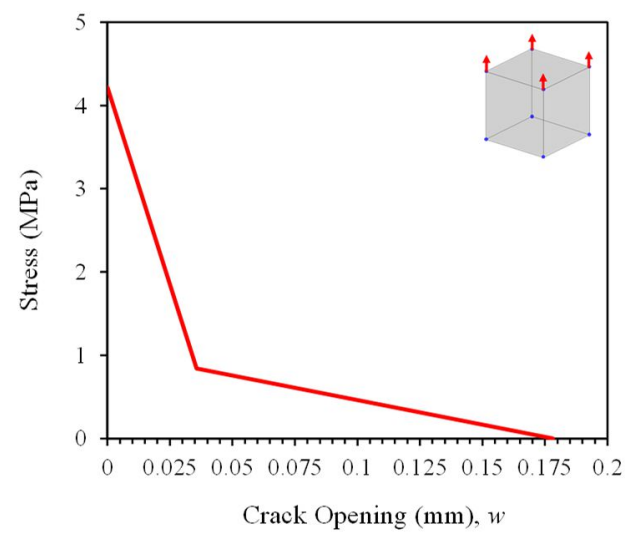

Fig 5. Fracture Energy Input of Concrete CDPM

\subsection{Steel Material}

To model steel material, material Piecewise Linear Plasticity (Mat 024) is incorporated into the FEA model. This material is capable to capture the elastoplastic bilinear hardening behavior of steel and incorporating isotropic hardening failure surface. The properties of steel material are given in Table 1 . No element deletion is allowed in this model.

Table 1. Steel Material Properties

\begin{tabular}{|c|c|c|}
\hline $\begin{array}{c}\text { Material } \\
\text { Properties }\end{array}$ & Nominal & Unit \\
\hline Mass Density, $\rho$ & 7700 & $\mathrm{~kg} / \mathrm{m}^{3}$ \\
\hline $\begin{array}{c}\text { Young's Modulus, } \\
E\end{array}$ & $2.10^{5}$ & $\mathrm{MPa}$ \\
\hline Poisson's Ratio, $v$ & 0,3 & - \\
\hline Yield Stress, $f_{y}$ & 363 & $\mathrm{MPa}$ \\
\hline $\begin{array}{c}\text { Tangent Modulus, } \\
E_{\text {tan }}\end{array}$ & $1.10^{3}$ & $\mathrm{MPa}$ \\
\hline
\end{tabular}

The type of steel rebar element incorporated in this study is the Hughes-Liu beam element following the formula developed by Hughes and Liu in 1981 [6]. The cross-section of each beam element is divided into 4 fiber elements. Each fiber element has 1 integration point. Thus, there are 4 integration points per steel beam's crosssection are 4 pieces.

\subsection{Bond Slip Interface Model}

To model the debonding process between steel reinforcement and concrete, a constrained beam in solid is invoked to provide constraint relaxation along the beam in the axial direction. The debonding force is applied based on the relative motion of the steel rebar. In applying the debonding force, a user-defined function is written in dyn. $\mathrm{f}$ is integrated into the FEA model as given in Fig. 5. Three bond-slip models are carried out, i.e., full bond model, bond-slip model following empirical bond-slip relation by Murcia-Delso [4], and bond-slip model following empirical bond-slip relation by Murcia-Delso with adjusted maximum bond stress. 


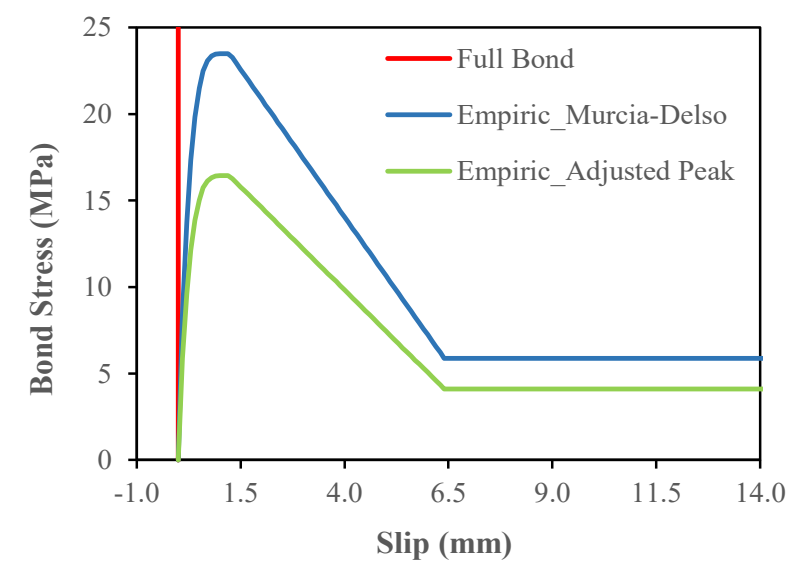

Fig 5. Three Bond-Slip models

\subsubsection{Model 1: Full Bond}

The first model is a full bond model. In the full bond model, constrained beam in solid is not applied as no bond-slip is allowed. The 3D solid concrete and 2D beam steel elements are sharing the nodes as the nodes are merged.

\subsubsection{Model 2: Empirical Bond-Slip}

In Model 2, the bond-slip is applied. The 3D solid concrete and 2D beam steel elements are constrained by using constrained beam in solid algorithm and userdefined load function as described in Section 3.4. The user-defined bond-slip relation follows the empirical equations proposed by Murcia-Delso [4] as shown in Fig. 5 . The peak bond stress $\left(\tau_{\max }\right)$ is given as a function of concrete compressive strength and the slip at which the peak bond stress is attained $\left(s_{\text {peak }}\right)$ is a function of bar diameter.

$$
\begin{aligned}
\tau_{\text {max }} & =1.163\left(f_{c}{ }^{\prime}\right)^{2 / 3} \\
s_{\text {peak }} & =0.07 d_{b}
\end{aligned}
$$

The bond stress at softening part is cut off at friction bond resistance of $0.25 \tau_{\max }$, when the slip occurred is beyond the clear spacing between deformed ribs $\left(s_{R}\right)$. For concrete with $55 \mathrm{MPa}$ compressive strength, the calculated $\tau_{\max }$ is $23.49 \mathrm{MPa}$.

\subsubsection{Model 3: Adjusted Empirical Peak Bond-Slip}

The peak bond stress proposed by Murcia-Delso in Model 2 , however, is higher than the observed bond stress of 16.43 MPa from the experiment [1]. This model is similar to Model 2 with adjustment in the peak bond stress. The peak bond stress is lowered to $16.43 \mathrm{MPa}$, yet the bondslip interface function still follows the empirical equations proposed by Murcia-Delso in Fig. 5.

\section{Numerical Results}

This section presents the numerical results obtained from FEM. Validation is provided by comparing numerical results obtained with the experimental data.
Tensile damage contour plots of the three models are given in Fig. 6. Red-colored solid elements show the bond zone area which experienced tensile damage.
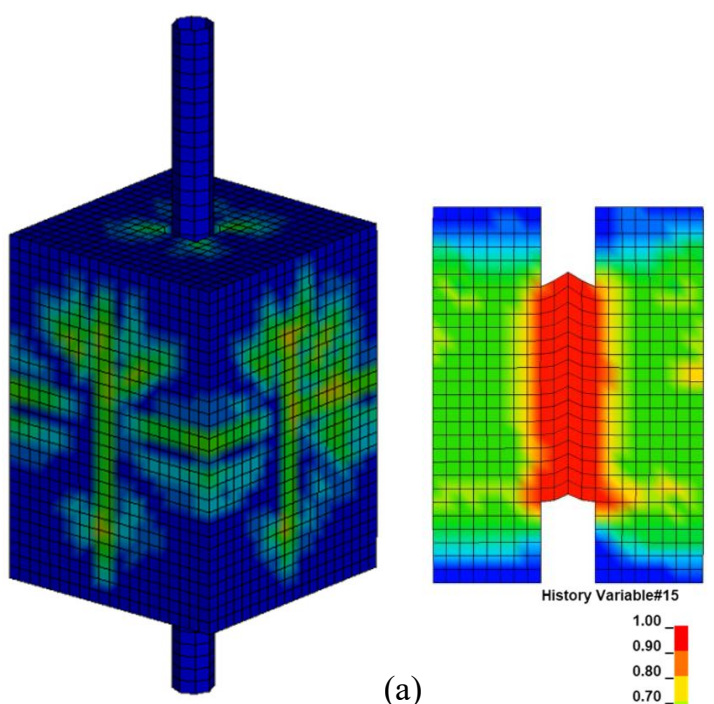

(a)
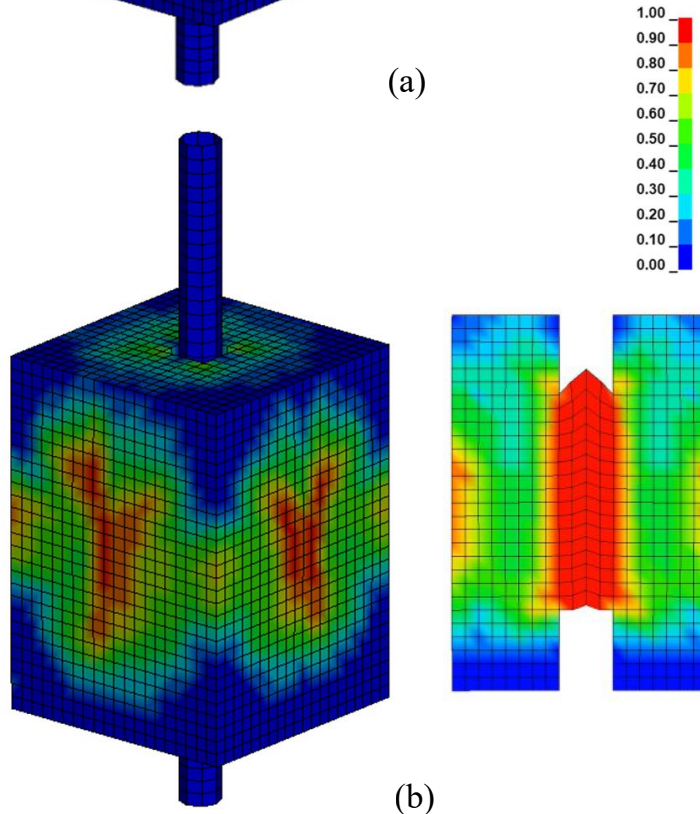

(b)

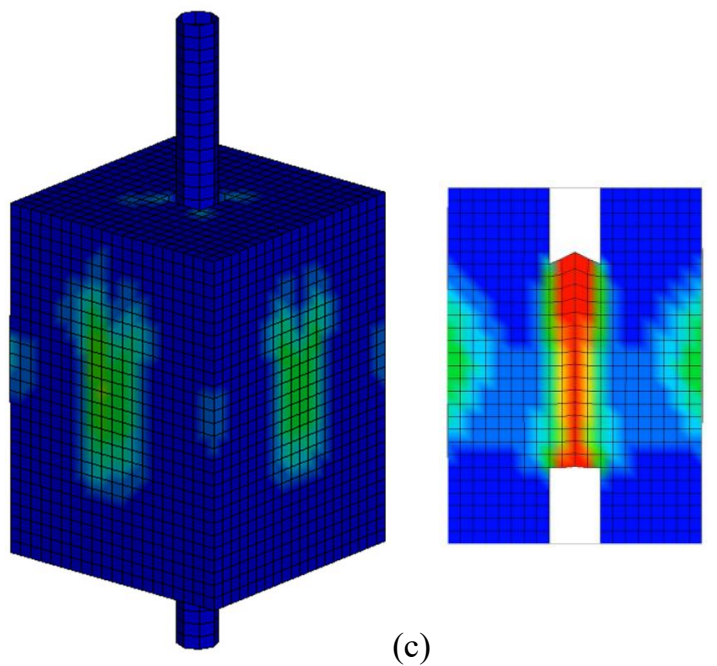

Fig. 6 Tensile Damage Contour at Final Stage of Loading of (a) Model 1: Full Bond, (b) Model 2: Empirical Bond-Slip, and (c) Model 3: Adjusted Empirical Peak Bond-Slip Specimens Subjected to Monotonic Pull-out Test 
From the tensile damage contour of Model 1 and 2 as illustrated in Figs. 6(a) and (b)), the damage has spread to the concrete area adjacent to the bond zones. On the other hand, in Model 3 the bond zone is localized and has not spread. Therefore, it is observed that Model 3 which incorporates bond-slip with adjusted empirical peak bond is in good agreement with the bond failure pattern of the specimen from the experiment as shown in Fig. 1, hence, it provides more realistic measures.
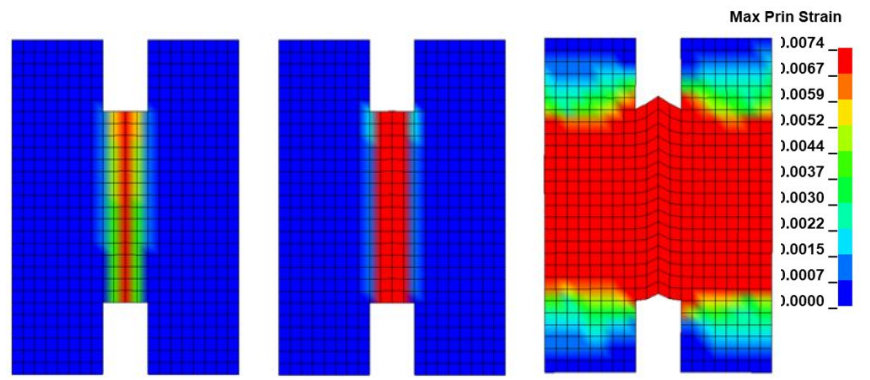

(a)
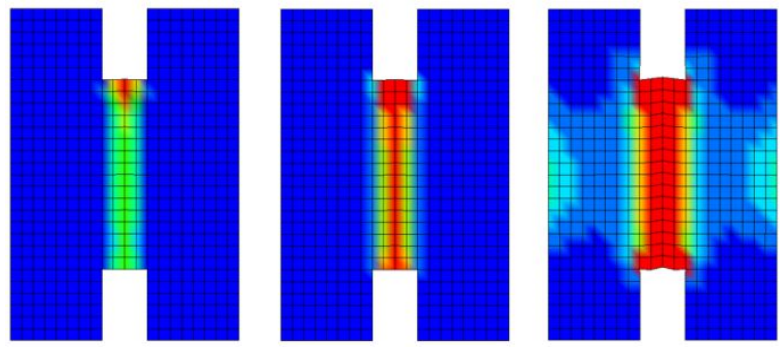

(b)
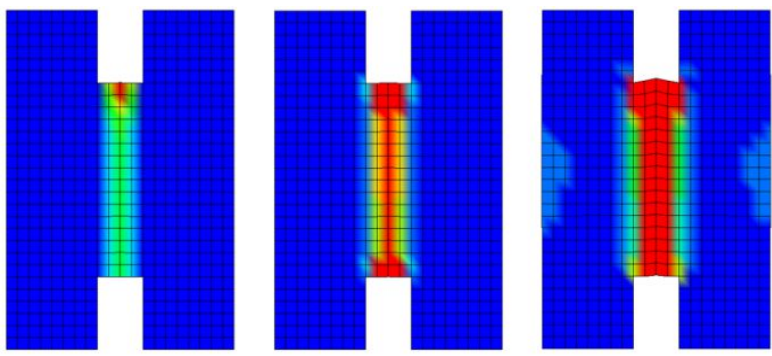

(c)

Fig. 7 Maximum Principal Strain Contour in MPa at Initial Stage (Left), Peak Bond Stress (Middle) and Final Stage (Right) of Loading of (a) Model 1: Full Bond, (b) Model 2: Empirical Bond-Slip, and (c) Model 3: Adjusted Empirical Peak Bond-Slip Specimens Subjected to Monotonic Pull-out Test

Maximum principal strains and minimum principal stresses contours of the three models are plotted and given in Figs. 7 and 8, respectively. Fig. 7 shows no splitting failure has occurred towards the transverse direction of the loading. It agrees well with the experimental result in Fig. 1. Conforming the damage observed in Fig. 6, similarly, the damage is found to be more localized around the bond zones for Model 2 and within the bond zones for Model 3 in Fig. 7. The maximum principal strain contour observed in Model 1 is, quite unrealistic as significantly large strains are observed to spread to the outer surface of the confined concrete region due to the full bond action.
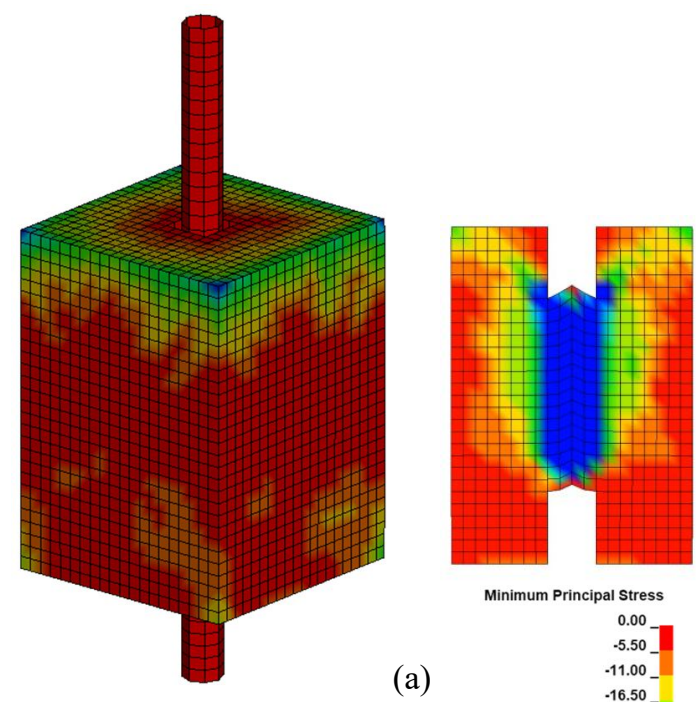

(a)
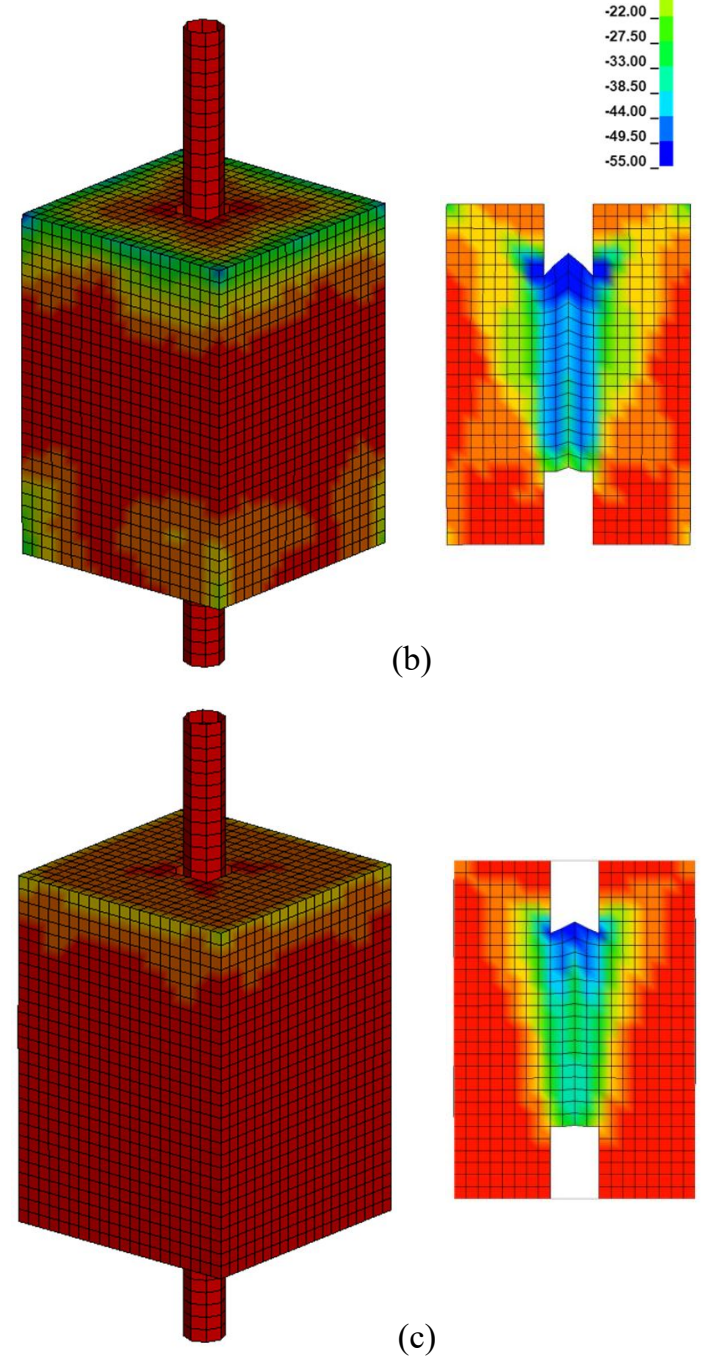

Fig. 8 Minimum Principal Stress Contour in MPa at Peak Bond Stress of (a) Model 1: Full Bond, (b) Model 2: Empirical BondSlip, and (c) Model 3: Adjusted Empirical Peak Bond-Slip Specimens Subjected to Monotonic Pull-out Test

In Fig. 8, the formations of inclined compression cone struts are observed. In the full bond model (Model 1), the compression struts have spread to adjacent concrete outside of the bond zone. On the other hand, the 
compression cone struts of Models 2 and 3 in Fig. 8 that incorporate bond slips stay within the bond zones.

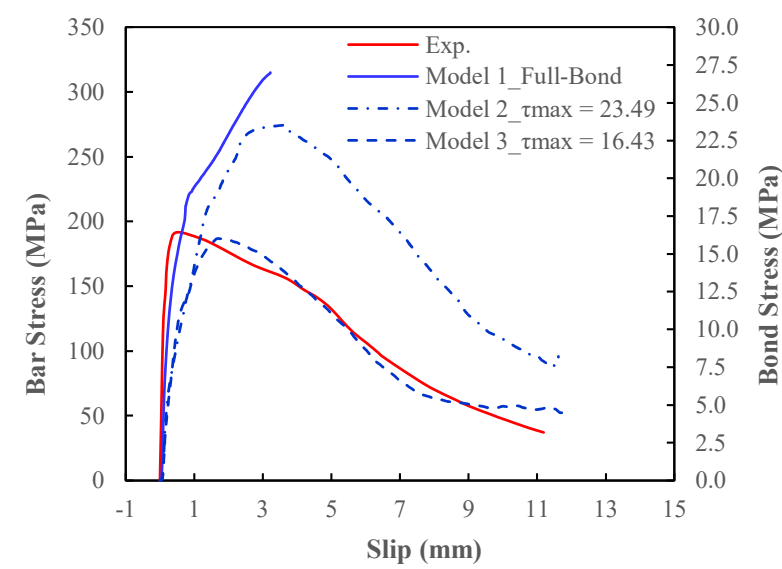

Fig. 9 Bar and Bond Stresses vs Slip

The bar and bond stresses of the three models and the experiment are plotted against the slip and given in Fig. 9. All the bar stresses are observed to have a value below the yield stress of $363 \mathrm{MPa}$. The full bond Model 1 overestimates the bar and bond stresses by $66.5 \%$. Similarly, Model 2, the bond-slip model with MurciaDelso empirical bond-slip relation, provides an overestimation of $44.6 \%$ when compared to the experimental result. Of the three models, Model 3, i.e., the bond-slip model with adjusted peak bond, can capture the bond-slip behavior better. The bar and bond stresses obtained from Model 3 are similar to those obtained from the experiment with only $1.2 \%$ error.

\section{Conclusions}

This paper investigates the behavior of the monotonic pull-out test of the deformed steel embedded into a well confined concrete specimen. Finite element analyses are carried out in three models and the results obtained are benchmarked against the experimental results available in the literature.

It is found that Model 3 of the bond slip model with adjusted peak bond provides a better estimate than the full bond of Model 1 and bond-slip Model 2 using MurciaDelso empirical equations. Good agreement is observed between Model 3 with the adjusted empirical peak bondslip and the experiment in terms of bond stress and rebar stress-slip response. The full bond model, as expected, provides overestimation to the response, providing higher rebar stress. In the bond-slip models, the empirical equation of bond-slip proposed by Murcia-Delso and Shing (2014) is found to overestimate the peak bond and bar stress.

\section{References}

1. S. Xu, A. Li, and H. Wang, "Bond properties for deformed steel bar in frost-damaged concrete under monotonic and reversed cyclic loading," Construction and Building Materials, 148, 344-358 (2017)

2. L.J. Malvar, "Bond of reinforcement under controlled confinement," ACI Material Journal, 89, 6, 593-601 (1992)

3. H. Sezen, J.P. Moehle, "Bond-Slip Behavior of Reinforced Concrete Members," Proceedings of the fib 2003 Symposium, Athen, Greece (2003)

4. J.Murcia-Delso, P.B. Shing, "Bond-slip model for detailed finite-element analysis of reinforced concrete structures," Journal of Structural Engineering, 141, 4 (2014)

5. D. P. Flanagan, T. Belytschko, "A uniform strain hexahedron and quadrilateral with orthogonal hourglass control," Numerical Methods in Engineering, 17, 5, 679-706 (1981).

6. T.J. Hughes, W.K. Liu, "Nonlinear finite element analysis of shells: Part I. Three-dimensional shells. Computer methods in applied mechanics and engineering,'26, 3, 331-362 (1981) 